\title{
Validação da Bateria de Avaliação da Memória de Trabalho (BAMT-UFMG)
}

\author{
Guilherme Maia de Oliveira Wood \\ Maria Raquel Santos Carvalho \\ Rui Rothe-Neves \\ Vitor Geraldi Haase \\ Universidade Federal de Minas Gerais
}

\begin{abstract}
Resumo
A memória de trabalho pode ser concebida em termos de sistemas de armazenamento ou por meio de modelos processuais ou dinâmicos. Nós adaptamos, para uso com a população brasileira, uma bateria de testes baseada em um modelo que divide a memória de trabalho em três aspectos: eficiência ou velocidade de processamento, armazenamento temporário e coordenação de operações. O exame das características psicométricas do instrumento, aplicado em 832 participantes de diversas faixas etárias e níveis educacionais, revelou sua adequação para uso em nosso meio, preservando as características do procedimento original e mostrando coeficientes aceitáveis de fidedignidade e de validade. O desempenho nos testes se correlacionou com o desempenho em testes de função executiva e de inteligência fluida, mas não se correlacionou com testes de memória associativa episódica. O programa de pesquisa deve continuar com o exame da utilidade clínica da BAMT-UFMG em neuropsicologia.

Palavras-chave: Memória de trabalho; executivo; inteligência; processamento; velocidade.
\end{abstract}

Validation of a Battery for Working Memory Assessment (BAMT-UFMG)

\begin{abstract}
Working memory may be conceived in terms of storing systems or by means of models of dynamic processes. We adapted a working memory assessment procedure based on a process model for use in Brazil. The model conceives working memory as three interrelated aspects: processing speed or efficiency, temporary storage and coordinative capacity. Results with 832 participants of several ages and educational levels indicate that the procedure is adequate to be used in our cultural environment, preserving the original characteristics and displaying acceptable reliability and validity characteristics. Working memory performance correlated with measures of executive function and fluid intelligence but not with measures of associative episodic memory. This research program will be pursued further examining the clinical neuropsychological usefulness of the BAMT-UFMG.

Keywords: Working memory; executive; intelligence; speed; processing.
\end{abstract}

A primeira dificuldade enfrentada por quem se dispõe a trabalhar com neuropsicologia no Brasil é a relativa escassez de instrumentos validados disponíveis para pesquisa e diagnóstico. O segundo problema não é exclusividade da neuropsicologia brasileira, é bem mais complexo e decorre em parte daquilo que Pasquali (1997) denomina de tradição positivista da psicometria e em parte da natureza indireta dos métodos inferenciais utilizados em correlação anátomo-funcional (Haase, 2000). Estes dois fatores concorrem para dificultar a validação de construto dos instrumentos neuropsicológicos. Neste artigo são relatados os resultados

\footnotetext{
${ }^{1}$ Endereço para correspondência: Departamento de Psicologia, FAFICH/UFMG, Av. Antonio Carlos 6627, 31270-901, Belo Horizonte, Brasil, Fone: (31) 4996295. E-mail: haase@fafich.ufmg.br
}

de um programa de pesquisa iniciado em 1996 com o intuito de desenvolver e validar uma Bateria para a Avaliação da Memória de Trabalho, a BAMT-UFMG. Iniciamos pelas questões relativas aos construtos subjacentes.

\section{O Construto Psicológico Memória de Trabalho}

Em ciências cognitivas ocorre atualmente uma mudança lenta e gradual, porém inexorável, de paradigma. Os modelos teóricos mais tradicionais, baseados na teoria do processamento de informação e em modelos da inteligência artificial clássica estão sendo substituídos por concepções derivadas dos modelos de redes neurais e de construtos da dinâmica não-linear (ver p. ex., Del Nero, 1997; Haken \& Haken-Krell, 1997; Teixeira, 1998). Estas transformações teóricas implicam 
também em profundas modificações no modo como os construtos são medidos, seja para fins de pesquisa, seja para aplicações clínicas, como no contexto da avaliação neuropsicológica. A memória de trabalho é um construto que não foge a esta regra, ilustrando tanto as vantagens quanto às dificuldades de pensar dinamicamente em neuropsicologia. Segundo a formulação original de Baddeley (1992a, 1992b), a memória de curta duração não se constitui apenas em um reservatório temporário de informação, mas cumpre também um papel ativo, executivo no seu processamento. Baddeley concebeu o modelo canônico de organização da memória de trabalho como um sistema tripartite de armazenamento constituído de um executivo central e dois sistemas escravos: uma alça fonológica, relacionada à representação e recitação do material verbal, e um sistema tampão visuo-espacial, o equivalente imagético da alça fonológica. As propriedades dos dois sistemas escravos estão relativamente bem caracterizadas, inclusive o seu papel no desenvolvimento normal e patológico e o seu funcionamento após lesões em diversas áreas cerebrais (ver p. ex., Baddeley, 1992a, 1992b; Gathercole, 1998; Torgesen, 1996).

O estatuto do executivo central é mais problemático. A começar pelo fato de que até hoje não surgiu, no âmbito do modelo canônico, uma tarefa de testagem que se prestasse a avaliar convincentemente suas características de funcionamento. Devido a essa obscuridade, o executivo central mais parece uma espécie de nebulosa que fica pairando sobre o sistema e se comporta de modo intencional sempre que necessário (ver p. ex., Haase, 2000). A partir de uma perspectiva dinâmica não há a necessidade de postular uma subdivisão entre sistemas de armazenamento e sistemas executivos. Segundo esta perspectiva, o correlato neural da atividade mental corresponde a uma ampla rede associativa, distribuída por córtex e subcórtex, onde as próprias áreas responsáveis pelo processamento sensorial e motor, funcionando em sincronia com as áreas associativas, são responsáveis simultaneamente tanto pelo "armazenamento" ou "representação", quanto pelo "processamento informacional" ou "funcionamento executivo". Na perspectiva dinâmica, o comportamento e a experiência subjetiva são o resultado de uma atividade construtiva, envolvendo não apenas o cérebro, mas também todo o organismo, bem como o contexto.

Do ponto de vista empírico, o modelo tripartite de Baddeley (1992a, 1992b) apresenta também algumas dificuldades. Por exemplo, para acomodar os dados de pesquisa indicando a ocorrência de diversos tipos de interações entre memória de longa duração e memória de trabalho (Recht \& Leslie, 1988; Schneider, Korkel \& Weinert, 1989). Alguns autores chegam a falar em "memória de trabalho de longa duração" (Ericsson \& Kintsch, 1995). A dificuldade principal, no entanto, diz respeito à necessidade de localizar e subdividir o sistema executivo. Os dados obtidos em estudos de neuroimagem funcional indicam, por exemplo, que múltiplas áreas cerebrais distintas são sincronicamente ativadas dependendo tanto do contexto, da natureza da tarefa, quanto da fase da vida (ver p. ex., Carpenter, Just \& Reichle, 2000; Reuter-Lorenz e cols., 2000). A realização de uma mesma tarefa por adultos jovens e idosos implica no recrutamento de áreas corticais distintas, inclusive quanto à sua lateralidade (Reuter-Lorenz e cols., 2000). Problemático também é o estatuto da relação entre o modelo psicológico e sua realização no nível neural. Com base em uma série de dados anatômicos e neurofisiológicos, Goldman-Rakic (1996) tem advogado uma relação quase direta entre o modelo de Baddeley e a estrutura morfofuncional do cérebro. Esta autora registrou a atividade de neurônios que exibem campos de memória em diversas áreas dos lobos pré-frontais. Em tarefas envolvendo retardos temporais, tais neurônios exibem um padrão de atividade que parece sinalizar algumas características sensoriais importantes dos estímulos discriminativos. Os dados de Goldman-Rakic apontam para uma subdivisão do sistema tampão visuoespacial em dois. Um sistema, conectado ao lobo parietal, tem seu polo executivo na área dorso-lateral do córtex frontal e é responsável pelo processamento espacial. O outro foco executivo se localiza na região ventro-lateral do córtex pré-frontal, processa padrões para o reconhecimento visual e se conecta com áreas do lobo temporal. Estes dados são complementados por estudos com neuro-imagem funcional indicando que a área de Broca em humanos pode ser o polo executivo de um sistema fonológico de memória de trabalho (ver p. ex., Smith \& Jonides, 1998). Estes achados parecem corroborar o modelo canônico, mas são refutados por outras evidências em animais e humanos indicando que as áreas em questão não são organizadas modularmente de acordo com o tipo de estímulo ou representação sensorial processada, mas sim de acordo com a natureza do processo implementado. De acordo com Petrides (1995), por exemplo, as áreas ventro-laterais na região do sulco arqueado são recrutadas por tarefas que requeiram a organização ativa de respostas com base em resgate consciente e explícito de representações oriundas das áreas corticais posteriores. Enquanto isto, as áreas dorso-laterais estariam envolvidas em tarefas propriamente executivas, ou seja, aquelas que exigem uma 
carga extra de processamento na memória de trabalho (ver ainda Owen, 1997; Owen e cols., 1998). Uma dificuldade adicional é o fato de que se o executivo central começar a ser fracionado, o construto acabará se esvaziando, uma vez que terminaremos lidando com uma série de fragmentos, os quais vão requerer um mecanismo adicional - executivo? - de integração. Ou seja, se por um lado no modelo de Baddeley o executivo central remete a uma entidade fantasmagórica, por outro lado, as tentativas de fracionamento e localização resultam em fragmentação.

Todas estas inconsistências sugerem que a memória de trabalho pode ser melhor concebida a partir de uma perspectiva processual (cf. Cowan, 1988), em que a atenção ou o foco da atividade mental consciente ou de monitorização é representada pela assembléia neuronal distribuída e variável de acordo com a estrutura contextual e que se encontra ativa em um determinado momento. A memória de trabalho seria representada por uma franja, também variável, de atividade com menor intensidade ou exibindo menor grau de coerência, mas que contribui expressivamente ainda que de modo implícito para a execução da tarefa. Finalmente, a memória de longa duração constitui-se naquela imensa rede reunindo os fragmentos de experiência que constituem os hábitos de um indivíduo, suas disposições comportamentais, conhecimento factual e estratégico etc., que representam recursos potencialmente recrutáveis a qualquer momento (vide Figura 1).

Como operacionalizar estes construtos derivados das teorizações dinâmicas de modo a possibilitar a sua

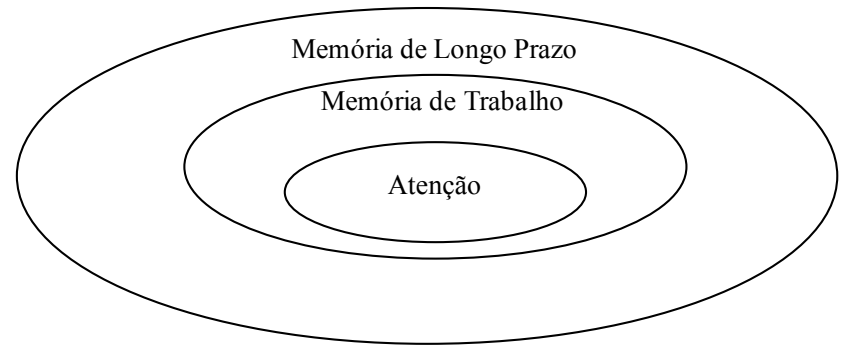

Figura 1. Concepção dinâmica das interrelações entre os processos atencionais, de memória de trabalho e de memória associativa de longo-prazo (modificada a partir de Cowan, 1988)

mensuração experimental e/ou psicométrica? Uma perspectiva que parece promissora é um modelo operacionalizado por Salthouse e Babcock (1991). Este modelo concebe a memória de trabalho em termos de algumas características dos processos componentes, principalmente sua dinâmica temporal. A primeira característica é a eficiência de processamento, Psicologia: Reflexão e Crítica, 2001, 14(2), pp. 325-341 operacionalizada como velocidade de processamento. A velocidade de processamento tem sido postulada como fator de mediação entre o construto psicológico da inteligência fluida e a sua base biológica (Deary \& Caryl, 1997; Rijsdijk, Vernon \& Boomsma, 1998), bem como do desenvolvimento e envelhecimento cognitivo ligado às funções executivas (Birren \& Fisher, 1995, Fry \& Hale, 1996; Salthouse \& Babcock, 1991; Salthouse, 1996). Salthouse (1996) considera que a capacidade de seqüenciamento de operações pode ser explicada em função da velocidade de processamento. Quanto mais rapidamente forem executadas as operações mentais, maior será a capacidade de armazenamento em um dado momento psicológico. A segunda característica corresponde a um processo propriamente dito e consiste na capacidade de armazenamento temporário, dependente de descargas neuronais sustentadas em células distribuídas ao longo de uma rede de retroalimentação amplamente distribuída por regiões corticais e subcorticais (Fuster, 1995; Goldman-Rakic, 1996). Finalmente, a última característica consiste na capacidade de coordenação entre as diversas operações, principalmente coordenação entre armazenamento e execução de operações de solução de problemas, correspondendo ao aspecto verdadeiro "executivo" do modelo. Salthouse (1996) considera que a capacidade de coordenação depende de mecanismos simultâneos de integração. Do ponto de vista neurobiológico existem diversas propostas sobre como isto poderia ocorrer a partir da organização do timing na atividade neuronal. Estas propostas variam desde o mecanismo de sincronização oscilatória proposto por Singer (ver p. ex., Singer, 1998; vide também Sarnthein, Petsche, Rappelsberger, Shaw \& von Stein, 1998) até o mecanismo de integração por oscilações periódicas proposto por Pöppel (ver p. ex., Pöppel, 1994; revisto por Haase, Diniz \& da Cruz, 1997).

O modelo de memória de trabalho operacionalizado por Salthouse e Babcock (1991) oferece grandes atrativos, portanto, do ponto de vista da sua validade de construto. Por um lado, o modelo foi psicometricamente operacionalizado, como veremos a seguir, de um modo que permite seu mapeamento em uma das formas de inteligência psicométrica, a inteligência fluida, justamente aquela forma de inteligência que se acredita ter uma maior fundamentação genético-biológica. Ao mesmo tempo, um dos conceitos fundamentais do modelo é representado pela velocidade de processamento, que, não por acaso, parece mediar as relações entre biologia e inteligência. Por outro lado, a natureza dos processos definidos permite correlacioná-los com dados empíricos a respeito do papel das descargas neuronais sustentadas 
na memória de trabalho. Permite também correlacionálos com modelos mais recentes oriundos da dinâmica cerebral que procuram explicar o funcionamento executivo em termos de mecanismos neuronais ao nível celular.

Passamos então a relatar os nossos esforços para verificar a adequação empírica dos procedimentos operacionais propostos por Salthouse e Babcock (1991) à nossa realidade cultural, bem como para verificar suas características psicométricas.

\section{Método}

\section{Participantes}

A amostra total se constituiu por 832 pessoas recrutadas da comunidade em geral e que participaram voluntariamente no estudo após esclarecimento dos seus objetivos, por intermédio de carta aos pais no caso de menores, e assinatura de termo de consentimento informado. A amostra total foi subdivida em seis subamostras, estudadas em momentos diferentes e recrutando pessoas de diversas faixas etárias e níveis educacionais (vide Tabela 1). Os procedimentos de testagem foram aplicados em pessoas de ambos os sexos com idades variando entre 11 e 85 anos e com níveis educacionais distribuídos entre 3 e 19 anos de escolarização formal (vide Tabela 2). A amostragem não foi aleatória, mas a amplitude de variação da idade e escolarização formal sugere que ela tenha alguma representatividade. A maior dificuldade encontrada foi para recrutar adultos jovens com baixa escolarização formal e idosos com escolarização formal mais alta.

\section{Instrumentos}

Bateria de Avaliação da Memória de Trabalho (BAMTUFMG): A BAMT-UFMG foi adaptada por Wood, Haase e Rothe-Neves (ver Wood e cols., 2000; RotheNeves, 2000) a partir de modificações dos procedimentos originais descritos por Salthouse e Babcock (1991). A BAMT-UFMG é um procedimento de lápis e papel, consistindo de tarefas relativamente simples, do conhecimento de qualquer pessoa alfabetizada. A BAMTUFMG se constitui de dois conjuntos de três tarefas homólogas empregando estímulos numéricos e verbais e medindo cada um dos três construtos do modelo de memória de trabalho (vide Tabela 3). O teste pode ser aplicado tanto individualmente quanto em grupo (Wood e cols., 1999). Apesar de as tarefas serem simples, a carga de processamento vai sendo progressivamente aumentada até atingir o limite da capacidade de processamento. Esta versatilidade está nos encorajando a investigar também a utilidade clínica da BAMT-UFMG.

Tabela 1. Sumário Descritivo das Amostras Estudadas

\begin{tabular}{cllr}
\hline No. da Amostra & Descrição & Faixa Etária & $n$ \\
\hline & & & \\
2 & Estudantes de $1^{\circ}$ e $2^{\circ}$ Graus - Colégio Militar & Estudantes de $1^{\circ}$. e 2 ${ }^{\circ}$. Grau & 592 \\
3 & Estudantes do $2^{\circ}$ grau - Escolas Públicas & & 87 \\
4 & Estudantes de Psicologia & Adultos Jovens Universitários & 56 \\
5 & Estudantes do CPOR & & 31 \\
6 & Idosos (Treinamento em Grupo) & & 44 \\
Total & Idosos (Treinamento Individual) & 22 \\
& & & 832
\end{tabular}

Tabela 2. Principais Características Demográficas das Seis Amostras Estudadas

\begin{tabular}{|c|c|c|c|c|c|c|c|c|c|c|}
\hline \multirow[t]{2}{*}{$\begin{array}{c}\text { No. } \\
\text { da Amostra } \\
\end{array}$} & \multirow[t]{2}{*}{$n$} & \multicolumn{4}{|c|}{$\begin{array}{l}\text { Idade } \\
\text { (Anos) }\end{array}$} & \multicolumn{4}{|c|}{$\begin{array}{l}\text { Escolaridade } \\
\text { (Anos) }\end{array}$} & \multirow[t]{2}{*}{$\begin{array}{c}\text { Sexo } \\
\text { Feminino } \\
(\%)\end{array}$} \\
\hline & & Mín. & Máx. & Média & $d p$ & Mín. & Máx. & Média & $d p$ & \\
\hline 1 & 592 & 11 & 17 & 14,00 & 1,82 & 05 & 10 & 7,62 & 1,81 & 43 \\
\hline 2 & 87 & 16 & 41 & 19,72 & 3,66 & 11 & 11 & 11,00 & 0,00 & 72 \\
\hline 3 & 56 & 17 & 36 & 20,84 & 4,10 & 11 & 19 & 12,71 & 2,04 & 77 \\
\hline 4 & 31 & 18 & 20 & 19,06 & 0,44 & 11 & 17 & 12,42 & 1,03 & 00 \\
\hline 5 & 44 & 51 & 85 & 66,27 & 7,67 & 03 & 16 & 07,20 & 3,59 & 84 \\
\hline 6 & 22 & 56 & 85 & 65,86 & 8,82 & 04 & 16 & 07,73 & 4,34 & 86 \\
\hline
\end{tabular}


O construto capacidade de coordenação foi desenvolvido a partir de um procedimento inicialmente descrito por Daneman e Carpenter (1980). Na modalidade "alcance de compreensão na escuta" (ALCESC), o participante vai escutando uma série de frases e deve responder por escrito no seu caderno de resposta a perguntas que vão sendo feitas para testar a compreensão de cada uma das frases. Ao mesmo tempo, o indivíduo deve reter temporariamente na memória a série constituída pelas últimas palavras de cada frase (vide Figura 2). Este sub-teste congrega, portanto, simultaneamente uma tarefa de compreensão de frases e

Tabela 3. Estrutura da BAMT-UFMG

\begin{tabular}{ccc}
\hline Componente Funcional & Tarefas Numéricas & Tarefas Verbais \\
\hline Capacidade de & ALCCOM & ALCESC \\
Coordenação & Alcance de & Alcance de Compreensão na \\
& Computação & Escuta \\
Capacidade de & APRD & APRP \\
Armazenagem & Listas de Números & Listas de Palavras \\
Eficiência de & ATM & SENT \\
Processamento & Compreensão & Compreensão de Frases \\
& Aritmética & \\
\hline
\end{tabular}

\begin{tabular}{|ll|}
\hline \multicolumn{3}{|c|}{ a) Alcance de Computação } & (ALCCOM) \\
AUDIÇÃO & VISÃO \\
5 mais 3 é igual a & -3 \\
& -7 \\
3 menos 2 é igual a & -4 \\
& -1 \\
3 mais 4 é igual a & -2 \\
& -6 \\
& -7 \\
\hline
\end{tabular}

vire a página

e transcreva AUDIÇÃO

b) Alcance de Compreensão na Escuta (ALCESC)

$\begin{array}{ll}\text { Suas amigas acham que se confundiram } & \text { VISÃO } \\ \text { com a roupar } & \text { Quem? }\end{array}$
com a roupa.

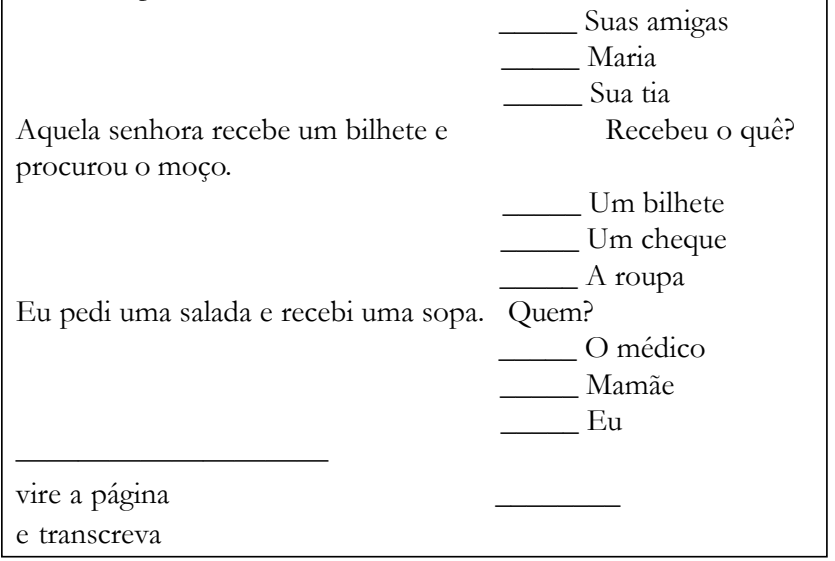

Figura 2. Amostras dos itens utilizados para as tarefas de coordenação (amostras com três problemas) outra de retenção de listas de palavras (word span). A versão numérica da tarefa de coordenação, chamada de "alcance de computação" (ALCCOM) consiste em responder a operações aritméticas oralmente formuladas, ao mesmo tempo em que o participante procura armazenar a lista com os últimos dígitos de cada problema (vide Figura 2). O tamanho das listas varia de uma a sete frases ou problemas aritméticos.

Nas tarefas de coordenação, os problemas são apresentados oralmente em velocidade normal de fala. Após a apresentação oral de cada problema o participante deve selecionar a resposta correta dentre três alternativas que constam em seu caderno de respostas. Completado um determinado número de problemas, o participante é instruído a escrever os números ou palavras finais de cada problema, na mesma ordem em que foram apresentados. O tempo de recordação permitido para cada item alvo é de aproximadamente quatro segundos. As instruções para os problemas enfatizam a necessidade de que o examinando responda corretamente aos problemas propostos e ao mesmo tempo priorize a recordação dos números ou palavras. É explicado aos participantes que as respostas não serão avaliadas caso haja erros na resolução dos problemas. Para cada tamanho de lista, em termos de número de itens, são apresentados três problemas. Considera-se que o examinando atingiu o critério em um determinado nível quando consegue responder a pelo menos dois dos três problemas corretamente. 
Os problemas aritméticos apresentam todos a seguinte estrutura, obedecendo às restrições do original (Salthouse \& Babcock, 1991): a) Todos os problemas são do tipo $\mathrm{X}+\mathrm{Y}=$ ou $\mathrm{X}-\mathrm{Y}=$, sendo que $\mathrm{X}$ e $\mathrm{Y}$ são números de um dígito variando de 1 a 9; b) As respostas para os problemas nunca são negativas; c) Y não pode ser igual para dois problemas dentro de uma mesma tentativa; d) A resposta para o problema não pode ser igual a Y; e) as duas alternativas de resposta incorretas oferecidas para os problemas são números entre 1 e 20 selecionados aleatoriamente; f) X e Y nunca são iguais.

As restrições originais descritas por Salthouse e Babcock (1991), para os problemas verbais foram mantidas e são as seguintes: a) as frases têm entre seis e dez palavras; b) a palavra final nunca é mais longa que duas sílabas; c) as palavras finais de cada frase devem ser suficiente comuns a ponto de constarem de dicionários infantis; d) nenhuma palavra aparece mais que uma vez como palavra final de uma frase durante o teste. Tentouse manter bastante simples as perguntas de cada frase. As perguntas foram do tipo "quem?, quando?, onde?". As alternativas de resposta nunca continham a palavra a ser recordada posteriormente. Embora não explícito por Salthouse e Babcock, os motivos teóricos dos critérios adotados são bastante conhecidos. A seguir, apresentamos esses motivos e os discutimos em dois níveis: lexical e sintático.

O comprimento de uma palavra está relacionado à capacidade de armazenamento: quanto maior a palavra, mais difícil de armazená-la (efeito de comprimento de palavra; Baddeley, Thomson \& Buchanan, 1975). O comprimento de uma palavra pode variar em quantidade de letras, fonemas ou sílabas. No que se refere à memória de trabalho, diz-se que o efeito de comprimento de palavra é dependente da estrutura da sílaba e não de suas características articulatórias (Caplan, Rochon \& Waters, 1992).

Da mesma forma, quanto mais freqüente é uma palavra no vocabulário da língua, mais fácil será compreendê-la (efeito de freqüência; Forster \& Chambers, 1973). Isto vale tanto para a freqüência de ocorrência simples quanto para a freqüência de co-ocorrência de complementos verbais (MacDonald, Pearlmutter \& Seidenberg 1994). Em português, verbos como "dizer" aceitam como complemento sintático um sintagma nominal ("Ela disse seu nome") ou uma oração subordinada ("Ela disse que está cansada"). Essas duas opções não são eqüiprováveis na língua e a mais freqüente é preferida. Esse tipo de efeito de freqüência parece ser responsável por uma expectativa de complemento do sujeito, seja em experimentos psicolingüísticos (Garnsey,
Pearlmutter, Myers, \& Lotocky, 1997; Trueswell, Tanenhaus \& Kello, 1993) seja em modelagem computacional (Pearlmutter, Daugherty, MacDonald \& Seidenberg, 1994).

Outras características que se sabem afetam a ativação lexical são as seguintes. Classe da palavra: o tempo médio de fixação do olhar na leitura é mais longo para verbos do que para substantivos (Rayner 1977; revisão em Rayner \& Sereno, 1994). Status semântico: baseado em potenciais evocados, Kounios e Holcomb (1994) descreveram um efeito de concretude, no qual substantivos concretos provocam maior negatividade entre $300-500 \mathrm{~ms}$ do que substantivos abstratos.

Para controlar a complexidade da frase, não basta que ela tenha entre seis e dez palavras. Frases complexas como a voz passiva (Gough, 1965; Slobin, 1966) e as orações relativas subjeito-objeto e objeto-objeto (Müller, King \& Kutas, 1997) são processadas de modo distinto, influenciando a capadidade da memória de sujeitos normais bem como em pacientes neurológicos (para revisão, ver Carpenter, Miyake \& Just, 1994). Portanto, a estrutura sintática também deve ser controlada, juntamente com seu comprimento em palavras. Isto já foi feito para população normal e neurológica (Caplan, Hildebrandt \& Makris, 1996; Rochon, Waters \& Caplan, 1994), com os resultados comparados ao alcance de leitura (reading span; Waters \& Caplan, 1996).

Em resumo, no nível lexical não apenas o comprimento e a freqüência de palavras afetam a memória de trabalho. Há boas razões para controlar a estrutura da sílaba, a classe, o status semântico da palavra final da frase (a ser lembrada), bem como a freqüência da opção de complemento do verbo. No nível sintático, controlam-se o comprimento da frase em palavras e também sua estrutura.

A capacidade de armazenamento é medida por tarefas de apreensão de listas de números ou digit span (APRD) e de apreensão de listas de palavras (APRP) ou word span. $\mathrm{O}$ tamanho das listas varia de dois a 11 itens. Nas tarefas de apreensão de listas, os estímulos são apresentados em uma taxa de, aproximadamente, um item por segundo e há um tempo máximo permitido de quatro segundos para recordação das listas para cada item de cada lista. Durante este tempo o participante deve transcrever a lista de itens para a folha de respostas. As listas de dígitos foram obtidas através de uma tabela de números aleatórios, sendo que dentro de listas de até nove números não houve repetições de números e nas listas de dez a 11 números os números não foram repetidos mais do que uma vez e nunca em posição adjacente. Não foi usado o número zero. As palavras usadas nas listas foram obtidas 
segundo os critérios de seleção aprimorados por RotheNeves (2000) e seguindo as mesmas restrições que as do teste alcance de compreensão na escuta, selecionadas em Pinheiro (1996).

A eficiência ou velocidade de processamento é medida, por outro lado, através do número de problemas que o indivíduo consegue responder em 20 segundos. A tarefa de compreensão aritmética (ATM) consiste de uma série de 27 problemas simples, similares àqueles do teste de coordenação apresentados em uma folha e aos quais o examinando deve responder por escrito. Já a tarefa de compreensão de frases (SENT) consiste em 25 problemas similares àqueles da tarefa de coordenação, também apresentados e resolvidos por escrito. São realizadas duas aplicações distintas dos testes de velocidade e considerada a média de respostas corretas em 20 segundos como o escore bruto.

É importante frisar que as habilidades, com a matemática ou com o português, exigidas pela BAMTUFMG são mínimas, podendo a bateria ser utilizada mesmo com indivíduos com menos de quatro anos de escolarização formal. Adicionalmente, a estrutura da bateria permite a obtenção de escores compostos combinando as transformações ₹ dos escores das tarefas. Seis escores compostos são possíveis pelo agrupamento dos escores brutos (vide Tabela 4). Os escores compostos são úteis quando se quer ter uma idéia do desempenho em cada um dos processos componentes, independentemente do tipo de estúmulo. $\mathrm{Ou}$, ao contrário, quando se quer ter uma idéia do nível do desempenho em função do tipo de estímulo empregado, ou ainda, quando o objetivo é obter um escore global de performance em memória de trabalho.

\section{Instrumentos para Validação Concordante e Discordante}

Com o intuito de investigar a validade concordante e discordante da BAMT-UFMG foram aplicados em algumas amostras outros instrumentos de testagem. Restrições de espaço não permitem uma descrição detalhada dos mesmos. Exceto para a escala avançada do teste de Raven $(1965,1997)$, foram adotados os procedimentos padronizados de aplicação referidos nos manuais. Para a escala avançada do teste das matrizes progressivas de Raven foi adotada uma sensibilização, reduzindo-se o tempo de aplicação de 40 para 20 minutos, pois estávamos interessados em investigar o papel da velocidade de processamento na inteligência fluida. A escala geral do teste de Raven obedeceu aos procedimentos padrões. Como medidas-critério para a validade concordante foram utilizados o teste da torre de Hanói (Klahr \& Robinson, 1980) e o teste de classificação de cartões de Wisconsin (WCST; Heaton, Chelune, Talley, Kay \& Curtiss, 1993; Heaton \& Thompson, 1993). A torre de Hanói empregava um problema com três argolas e o escore foi construído diminuindo-se um ponto de sete para cada dica que o participante precisasse para resolver o problema em duas tentativas. A torre de Hanói tem sido tradicionalmente considerada como um procedimento para avaliação da capacidade de memória de trabalho e, principalmente de planejamento e solução de problemas. O teste de Wisconsin mede construtos relacionados com a capacidade de categorização e flexibilidade nas operações cognitivas. No WCST, o escore considerado para fins estatísticos foi o número de categorias alcançadas pelo participante.

Como tarefas-critério para os estudos de validade discordante foram empregados dois procedimentos de avaliação da memória episódica, o teste de discriminação de listas (TDL-UFMG; Lacerda \& Haase, 2000) e um teste de associação de pares face-nome desenvolvido por Wood e colaboradores (2000) a partir de um procedimento descrito por McCarthy (1980). O TDLUFMG consiste em uma adaptação clínica de um procedimento experimental introduzido por Milner,

Tabela 4. Construção dos Escores Compostos

Tarefas componentes

Escores compostos

Escore de Coordenação

Escore de Armazenagem

Escore de Eficiência

de Processamento

Escore Numérico

Escore Verbal

Escore Geral
Alcance de Computação + Alcance na Escrita

Listas de Números + Listas de Palavras

Compreensão Aritmética + Compreensão de Frases

Alcance de computação, listas de números e compreensão aritmética

Alcance na escrita, listas de palavras e compreensão aritmética

Alcance de computação, listas de números, compreensão aritmética,

Alcance na escrita, listas de palavras e compreensão aritmética 
McAndrews e Leonard (1990) para avaliar um aspecto da memória contextual, a ordenação temporal dos eventos. Foram desenvolvidas duas versões do teste, uma usando figuras representando objetos comuns por meio de contornos de linha e outras palavras concretas. Para cada versão do teste é apresentada primeiramente uma lista com 10 estímulos, exibidos individualmente em cartões. Segue-se uma tarefa distratora, que consistem subtrair sucessivamente 7 de 100 e, logo após, apresentada uma segunda lista de estimulação. $\mathrm{Na}$ fase de testes são apresentados 20 cartões contendo sempre um estímulo novo e um estímulo já apresentado. O examinando deve identificar o estímulo que já foi apresentado (memória de reconhecimento - lobo temporal medial) e determinar se o mesmo apareceu na primeira ou na segunda lista, ou seja, antes ou depois da tarefa distratora (memória de recenticidade ou de ordem temporal - lobo frontal dorsolateral). A tarefa para avaliar a associação de pares face-nome consiste simplesmente na apresentação, durante a fase de estimulação, de 20 cartões onde aparecem um rosto de pessoa de meia idade ou idosa e um nome retirado do catálogo telefônico. $\mathrm{Na}$ fase de teste são apresentados as mesmas fotos de rostos, numa ordem diferente e sem os nomes. A tarefa dos probandos é tentar se lembrar o nome associado à pessoa. No caso da Amostra 6 (vide Tabelas 1 e 2), que incluiu os participantes de um estudo de treinamento cognitivo para seniores (descrito em Wood e cols., 2000), foi possível fazer medidas de correlação em duas ocasiões, no pré- e no pós-teste, entre os escores da BAMT-UFMG e as medidas-critério para validação concordante e discordante.

\section{Procedimentos}

Com exceção da Amostra 6 (vide Tabelas 1 e 2), para a qual a testagem foi individual, todos os outros procedimentos de testagem foram aplicados em grupos de 20 a 30 participantes. Em grupo, a aplicação de toda a BAMT-UFMG tem uma duração aproximada de 90 minutos, divididos em duas sessões espaçadas entre si por no mínimo 24 horas e no máximo duas semanas consecutivas. Os testes foram realizados em locais com luminosidade adequada e com o mínimo de ruído ambiente. Os examinandos foram bem acomodados e ouviam claramente a $\mathrm{vOz}$ do examinador. As instruções para a realização das tarefas da BAMT-UFMG são padronizadas e foram lidas completamente pelo examinador sem alterá-las. Caso houvesse alguma dúvida por parte dos participantes, o examinador repetia as instruções quantas vezes fossem necessárias. As tarefas da BAMT estão organizadas em dois cadernos padronizados de resposta, cada um contendo os testes concernentes à respectiva sessão de aplicação. Na primeira sessão são realizadas as seguintes tarefas: alcance de computação (ALCCOM), listas de números (APRD) e compreensão aritmética (ATM). Na segunda sessão, alcance de compreensão na escuta (ALCESC), listas de palavras (APRP) e compreensão de frases (SENT).

Tabela 5. Estatística Descritiva para os Escores Brutos Obtidos nas Tarefas da BAMT-UFMG, Teste de Raven, Torre de Hanói, Teste de Wisconsin e Tarefas do TDL-UFMG

\begin{tabular}{|c|c|c|c|c|c|c|c|c|c|c|c|c|c|}
\hline & ALCCOM & APRD & ATM & ALCESC & APRP & SENT & Raven* & TH & WSCT & RECPCT $\%$ & RECVBR $\%$ & RNTPCT $\%$ & RNTVRB $\%$ \\
\hline \multirow[t]{2}{*}{ Conc. } & 4,25 & 6,65 & 16,88 & 4,05 & 4,44 & 9,83 & . & . & . & . & . & 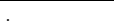 & 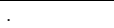 \\
\hline & 1,70 & 1,46 & 3,68 & 1,30 & 1,42 & 2,82 & . & . & . & . & . & . & . \\
\hline \multirow[t]{2}{*}{ Transf. } & 3,34 & 6,30 & 15,28 & 3,68 & 4,07 & 8,65 & . & . & . & . & . & . & . \\
\hline & 1,66 & 1,44 & 4,26 & 1,59 & 1,68 & 3,05 & & . & . & . & . & . & . \\
\hline \multirow[t]{2}{*}{ Secund. } & 3,97 & 6,51 & 15,47 & 3,11 & 4,24 & 7,76 & 18,51 & . & . & . & . & . & . \\
\hline & 1,94 & 1,78 & 3,58 & 1,76 &, 83 & 2,40 & 6,95 & . & . & . & . & . & . \\
\hline \multirow[t]{2}{*}{ Univ. } & 5,04 & 6,73 & 18,80 & 4,82 & 5,36 & 8,38 & . & . & . & . & . & . & . \\
\hline & 1,58 & 1,33 & 3,91 & 1,32 &, 96 & 2,27 & & . & . & . & . & . & . \\
\hline \multirow[t]{2}{*}{ CPOR } & 4,42 & 6,81 & 20,45 & 3,65 & 4,39 & 8,97 & . & . & . & . & . & . & . \\
\hline & 1,23 & 1,14 & 3,66 & 1,25 &, 76 & 2,59 & & . & . & . & . & . & . \\
\hline Idosos & 2,16 & 5,32 & 9,98 & 2,52 & 3,66 & 4,57 & 28,53 & & & & & & \\
\hline Grupo 1 & 1,68 & 1,16 & 5,33 & 1,52 & ,96 & 2,60 & 11,57 & . & . & . & . & . & . \\
\hline Idosos & 2,82 & 5,18 & 10,36 & 2,39 & 3,73 & 4,50 & & & & & & & \\
\hline Grupo 2 & 1,32 & 1,06 & 4,64 & 1,45 &, 59 & 2,22 & . & . & . & . & . & . & . \\
\hline Idosos & 2,23 & 5,00 & 9,50 & 2,09 & 3,95 & 3,68 & & 5,26 & 3,68 & 98,42 & 68,96 & 68,96 & 65,78 \\
\hline Indiv. 1 & 1,02 &, 87 & 3,74 & 1,06 & ,65 & 1,49 & & 1,33 & 2,33 & 3,36 & 15,22 & 9,10 & 14,14 \\
\hline Idosos & 2,45 & 5,23 & 10,73 & 2,23 & 4,09 & 4,50 & . & 6,28 & 4,00 & 98,24 & 71,46 & 89,71 & 59,66 \\
\hline Indiv. 2 &, 91 &, 97 & 4,74 & 1,19 &, 81 & 2,04 & . & 2,24 & 2,31 & 4,31 & 12,95 & 11,38 & 12,52 \\
\hline
\end{tabular}

Conc.- Estudantes de $1^{\circ}$ e $2^{\circ}$ graus Selecionados, Transf.- Estudantes de $1^{\circ}$ e $2^{\circ}$ graus Não-selecionados, Secund. - Estudantes de $2^{\circ}$ Grau, Univ.Estudantes de Psicologia, CPOR- Estudantes do CPOR, Idosos Grupo1- Idosos Treino em Grupo, Pré-teste, Idosos Grupo2- Idosos Treino em Grupo, Pós-teste, Idosos Indiv1- Idosos Treino Individual, Pré-teste, Idosos Indiv2- Idosos Treino Individual, Pós-teste, ALCCOM- Alcance de Computação, APRD- Listas de Números, ATM- Compreensão Aritmética, ALCESC- Alcance de Compreensão na Escuta, APRP- Listas de Palavras, SENT- Compreensão de Frases, Raven*- Raven Escala Geral para a amostra de Idosos e Escala Avançada para os Estudantes Secundaristas, TH- Tarefa da Torre de Hanói, WCST- Teste de Classificação dos Cartões de Wisconsin, RECPCT- Tarefa de Reconhecimento Pictorial, RECVRB- Tarefa de Reconhecimento Verbal, RNTPCT- Tarefa de Recenticidade Pictorial, RNTVRB- Tarefa de Recenticidade Verbal. 


\section{Resultados}

O estudo de validação da BAMT-UFMG foi dividido em três partes. Na primeira parte relatamos os resultados do cálculo dos coeficientes de fidedignidade, para depois descrever os resultados da análise fatorial e, finalmente, são descritos os dados de validade convergente e divergente. Os dados de estatística descritiva para todos os escores obtidos no estudo podem ser visualizados na Tabela 5.

\section{Escores de Fidedignidade}

A fidedignidade dos resultados obtidos com a BAMTUFMG foi avaliada por meio dos coeficientes de correlação de Spearman-Brown segundo a metodologia proposta por Salthouse e Babcock (1991). Com o intuito de excluir possíveis fraudes nas tarefas de coordenação foram considerados apenas os escores máximos obtidos em cada nível de dificuldade quando estes se acompanhavam de escores consistentemente corretos também para os níveis de menor dificuldade, o que foi medido através de correlações. No caso das tarefas de capacidade de armazenagem e de eficiência de processamento os escores brutos foram correlacionados com a soma do número de erros cometidos em cada tarefa. Os escores de fidedignidade para os diversos componentes da bateria situaram-se em faixas bastante satisfatórias de correlação, variando entre 0,797 e 0,984 (vide Tabela 6).

\section{Análise Fatorial}

Considerando os efeitos do envelhecimento sobre a memória de trabalho (vide Salthouse \& Babcock, 1991; Verhaegen \& Salthouse, 1997), foram conduzidos em separado dois procedimentos de análise fatorial com os escores brutos da BAMT-UFMG para os participantes jovens $(n=515)$ e para os participantes adultos e idosos $(n=153)$. O método de extração dos fatores utilizado foi o dos Componentes Principais estabelecendo em 1 o valor mínimo do Eigenvalor como ponto de corte para a exclusão de fatores dos modelos. Para a amostra jovem somente um fator alcançou Eigenvalor maior do que 1, o qual explicou pouco menos que $40 \%$ da variância (Tabela 7). Um segundo fator obteve um valor próximo, porém inferior a 1. Como mostram os dados da Tabela 8 , as cargas fatoriais das tarefas da BAMT-UFMG no

Tabela 6. Escores de Fidedignidade Calculados pela Fórmula de SpearmanBrown

\begin{tabular}{lr}
\hline Escores Brutos & Coeficiente de Fidedignidade \\
ALCCOM & 0,964 \\
APRD & 0,923 \\
ATM & 0,984 \\
ALCESC & 0,944 \\
APRP & 0,797 \\
SENT & 0,863 \\
\hline
\end{tabular}

ALCCOM - Alcance de Computação, APRD - Listas de Números, ATM Compreensão Aritmética, ALCESC - Alcance de Compreensão na Escuta, APRP - Listas de Palavras, SENT - Compreensão de Frases

Tabela 7. Análise Fatorial: Total da Variância Explicada para a Amostra de Jovens $(n=515)$

\begin{tabular}{ccccccc}
\hline Componente & $\begin{array}{c}\text { Eigenvalues } \\
\text { Iniciais } \\
\text { Total }\end{array}$ & $\begin{array}{c}\% \mathrm{da} \\
\text { Variância }\end{array}$ & $\begin{array}{c}\% \\
\text { Acumulado }\end{array}$ & $\begin{array}{c}\text { Extração da Soma dos } \\
\text { Quadrados das Cargas } \\
\text { Total }\end{array}$ & $\begin{array}{c}\% \mathrm{da} \\
\text { Variância }\end{array}$ & $\begin{array}{c}\% \\
\text { Acumulado }\end{array}$ \\
\hline 1 & 2,397 & 39,948 & 39,948 & 2,397 & 39,948 & \\
2 & 0,925 & 15,424 & 55,371 & & \\
3 & 0,835 & 13,921 & 69,293 & & \\
4 & 0,698 & 11,641 & 80,934 & & & \\
5 & 0,609 & 10,154 & 91,088 & & & \\
6 & 0,535 & 8,912 & 100,000 & & & \\
\end{tabular}

Método de Extração: Análise dos Componentes Principais. 
fator extraído foram moderadas para a amostra jovem. As cargas fatoriais das tarefas de coordenação e de eficiência de processamento foram as mais altas dentro do modelo. Esses resultados sugerem que as tarefas da BAMT-UFMG provavelmente estão associadas a um construto comum do qual medem aspectos diferentes, porém parcialmente superpostos.

Tabela 8. Análise Fatorial: Matriz dos Componentes para a Amostra de Jovens $(n=515)$

\begin{tabular}{ll}
\hline & Componente \\
\hline SENT & 1 \\
ALCCOM & 0,714 \\
ATM & 0,695 \\
ALCESC & 0,690 \\
APRD & 0,620 \\
APRP & 0,610 \\
\hline
\end{tabular}

Método de Extração: Análise dos Componentes Principais. ALCCOM - Alcance de Computação, APRD - Listas de Números, ATM - Compreensão Aritmética, ALCESC - Alcance de Compreensão na Escuta, APRP - Listas de Palavras, SENT Compreensão de Frases.
Para a amostra de indivíduos adultos e idosos somente um fator alcançou Eigenvalor maior do que 1, explicando cerca de $61 \%$ da variância (Tabela 9). Os dados da Tabela 10 indicam que as cargas fatoriais das tarefas da BAMTUFMG no fator extraído foram altas ou moderadamente altas, para a amostra de adultos e idosos. Novamente, as cargas fatoriais das tarefas de capacidade de coordenação e de eficiência de processamento foram as mais altas dentro do modelo. A consistência dos resultados obtidos com a análise fatorial nas duas amostras sugere que os processos medidos pelas tarefas da bateria refletem um construto comum, cuja estrutura não se altera qualitativamente em função da idade.

\section{Validade Convergente e Divergente}

A validade convergente e divergente para a BAMTUFMG, foi avaliada pelo grau de associação entre os seus escores e os escores em tarefas representativas de três outros construtos teóricos que apresentam diferentes graus de superposição e independência em relação ao construto da memória de trabalho, a saber: funções executivas (ver p. ex., West, 1996), memória associativa

Tabela 9. Análise Fatorial: Total da Variância Explicada para a Amostra de Adultos e Idosos $(n=153)$

\begin{tabular}{ccccccc}
\hline \multicolumn{3}{c}{$\begin{array}{c}\text { Eigenvalues } \\
\text { Iniciais }\end{array}$} & \multicolumn{3}{l}{$\begin{array}{l}\text { Extração da Soma dos } \\
\text { Quadrados das Cargas }\end{array}$} \\
\hline Componente & Total & \%da Variância & $\%$ Acumulado & Total & $\%$ da Variância \% Acumulado \\
& & & & & & \\
1 & 3,698 & 61,634 & 61,634 & 3,698 & & \\
2 & 0,708 & 11,805 & 73,439 & & & \\
3 & 0,614 & 10,234 & 83,673 & & \\
4 & 0,397 & 6,615 & 90,288 & & \\
5 & 0,338 & 5,639 & 95,928 & & \\
6 & 0,244 & 4,072 & 100,000 & & \\
\hline
\end{tabular}

Método de Extração: Análise dos Componentes Principais.

Tabela 10. Análise Fatorial: Matriz dos Componentes para a Amostra de Adultos e $\operatorname{Idosos}(n=153)$

\begin{tabular}{ll}
\hline & Componente \\
\hline & 1 \\
ATM & 0,833 \\
ALCCOM & 0,828 \\
SENT & 0,807 \\
ALCESC & 0,773 \\
APRP & 0,761 \\
APRD & 0,702 \\
\hline
\end{tabular}

Método de Extração: Análise dos Componentes Principais.

ALCCOM - Alcance de Computação, APRD - Listas de Números, ATM - Compreensão Aritmética, ALCESC - Alcance de Compreensão na Escuta, APRP - Listas de Palavras, SENT - Compreensão de Frases. 
de longa duração (ver p.ex., Wagner, 1996) e inteligência fluida (ver p. ex., Carpenter, Just \& Shell, 1990; Kyllonen \& Chrystal, 1990) (Tabela 11). As análises de correlação foram realizadas independentemente utilizando os escores brutos e os escores compostos da BAMT-UFMG. Como os resultados são praticamente os mesmos para os dois tipos de escore, optamos por apresentar os resultados relativos aos escores compostos, que melhor representam os construtos latentes (Tabela 12). Os escores da BAMT-
UFMG apresentam correlação positiva significativa apenas com os escores do WCST, sugerindo que o construto avaliado pela BAMT-UFMG está relacionado à capacidade de categorização e flexibilidade nas operações cognitivas. Dos três processos componentes da BAMT-UFMG, a capacidade de coordenação foi o que melhor se correlacionou com o desempenho no teste de Wisconsin $(r=0,720, p=0,001)$, seguido pelo escore de armazenamento $(r=0,476, p=0,01)$. A eficiência de

Tabela 11. Correspondência entre Construtos Teóricos, Tarefas Cognitivas Realizadas e Amostras Testadas

\begin{tabular}{|c|c|c|c|c|c|c|c|}
\hline \multirow{2}{*}{$\begin{array}{l}\text { Construtos Teóricos } \\
\text { Funções Executivas }\end{array}$} & \multicolumn{4}{|c|}{ Tarefas Cognitivas } & \multicolumn{3}{|c|}{ Amostras Testadas } \\
\hline & $\begin{array}{l}\text { Torre de Hanói } \\
(n=19) \\
\text { WCST } \\
(n=19) \\
\text { TDL-UFMG } \\
(n=19) \\
(n=17)\end{array}$ & & & & $\begin{array}{l}\text { Amostra } 6( \\
\text { Individual }{ }^{*} \\
\text { Amostra } 6 \\
\text { Individual)* } \\
\text { Amostra } 6 \\
\text { Individual)* }\end{array}$ & $\begin{array}{l}\text { dosos- } \mathrm{Tr} \\
\text { dosos- } \mathrm{Tr} \\
\text { dosos- } \mathrm{Tr}\end{array}$ & $\begin{array}{l}\text { amento } \\
\text { amento } \\
\text { amento }\end{array}$ \\
\hline Memória Associativa & \multicolumn{4}{|c|}{$\begin{array}{l}\text { Tarefa de Associação de Pares Face- } \\
\text { Nome } \\
(n=19)\end{array}$} & \multicolumn{3}{|c|}{$\begin{array}{l}\text { Amostra } 6 \text { (Idosos-Treinamento } \\
\text { Individual)* }\end{array}$} \\
\hline Inteligência Geral & \multicolumn{4}{|c|}{$\begin{array}{l}\text { Teste das Matrizes Progressivas de Raven - } \\
\text { Escala Geral } \\
(n=38) \\
\text { Teste das Matrizes Progressivas de Raven - } \\
\text { Escala Avançada } \\
(n=63)\end{array}$} & \multicolumn{3}{|c|}{$\begin{array}{l}\text { Amostra } 5 \text { (Idosos-Treinamento } \\
\text { em Grupos) }\end{array}$} \\
\hline \multicolumn{8}{|c|}{$\begin{array}{l}\text { WCST - Teste de Classificação de Cartões de Wisconsin, TDL-UFMG - Teste de Discriminação de Listas, *Amostra testada em duas } \\
\text { ocasiões distintas. }\end{array}$} \\
\hline \multicolumn{8}{|c|}{$\begin{array}{l}\text { Tabela 12. Correlações entre os Escores Compostos da BAMT-UFMG e as Tarefas-Critério para Avaliação da } \\
\text { Validade Convergente e Divergente }\end{array}$} \\
\hline$N=19$ & Torre de Hanói & Coord & Armaz & Effic & Num & Verb & Geral \\
\hline \multirow{3}{*}{ Funções Executivas } & & 0,358 & 0,442 & 0,203 & 0,292 & 0,394 & 0,368 \\
\hline & WCST & $\begin{array}{l}\text { n.s. } \\
0,720 * * *\end{array}$ & $\begin{array}{l}\text { n.s. } \\
0,476^{*}\end{array}$ & $\begin{array}{l}\text { n.s. } \\
0,445 \text { n.s. }\end{array}$ & $\begin{array}{l}\text { n.s. } \\
0,600^{* * *}\end{array}$ & $\begin{array}{l}\text { n.s. } \\
0,540^{*}\end{array}$ & $\begin{array}{l}\text { n.s. } \\
0,623 * *\end{array}$ \\
\hline & Reconhecimento Pictorial & $0,466^{*}$ & 0,089 & 0,355 n.s. & 0,257 & 0,417 & 0,359 \\
\hline \multirow{5}{*}{ Memória Episódica } & & & n.s. & & n.s. & n.s. & n.s. \\
\hline & Reconhecimento Verbal & 0,337 & 0,184 & 0,278 n.s. & 0,264 & 0,304 & 0,307 \\
\hline & Recenticidade Pictorial & $\begin{array}{l}\text { n.s. } \\
0,155\end{array}$ & $\begin{array}{l}\text { n.s. } \\
-0,107\end{array}$ & 0,092 n.s. & $\begin{array}{l}\text { n.s. } \\
0,076\end{array}$ & $\begin{array}{l}\text { n.s. } \\
0,040\end{array}$ & $\begin{array}{l}\text { n.s. } \\
0,064\end{array}$ \\
\hline & Recenticidade Verbal & $\begin{array}{l}\text { n.s. } \\
0,323\end{array}$ & $\begin{array}{l}\text { n.s. } \\
0,265\end{array}$ & 0,357 n.s. & $\begin{array}{l}\text { n.s. } \\
0,337\end{array}$ & $\begin{array}{l}\text { n.s. } \\
0,325\end{array}$ & $\begin{array}{l}\text { n.s. } \\
0,360\end{array}$ \\
\hline & $\begin{array}{l}\text { Associação de Pares Face- } \\
\text { Nome }\end{array}$ & $\begin{array}{l}\text { n.s. } \\
0,361 \\
\text { n.s. }\end{array}$ & $\begin{array}{l}\text { n.s. } \\
0,362 \\
\text { n.s. }\end{array}$ & 0,220 n.s. & $\begin{array}{l}\text { n.s. } \\
0,476^{*}\end{array}$ & $\begin{array}{l}\text { n.s. } \\
0,141 \\
\text { n.s. }\end{array}$ & $\begin{array}{l}\text { n.s. } \\
0,350 \\
\text { n.s. }\end{array}$ \\
\hline
\end{tabular}

Coord - Capacidade de Coordenação de Operações, Armaz- Capacidade de Armazenagem, Effic - Eficiência de Processamento de Informação, Num - Escore Numérico, Verb - Escore Verbal, Geral - Escore Geral, *Correlação Significativa ao nível de $p=0,05$; ** Correlação Significativa ao nível de $p=0,01$; *** Correlação Significativa ao nível de $p=0,001$, n.s.- correlação não significativa. 
processamento não se correlacionou com o WCST. A importância da correlação com o funcionamento executivo é confirmada pela falta de correlações com as medidas de memória associativa episódica. Por exemplo, as correlações entre o escore geral da BAMT e todos as tarefas de memória episódica ficaram abaixo de 0,360 e não foram significativas (vide Tabela 12). Ao contrário do esperado, não houve correlação significativa entre os escores na BAMT e o desempenho na torre de Hanói, tarefa que se presume avaliar tanto a memória de trabalho quanto a capacidade de planejamento. As correlações entre o desempenho no teste da torre de Hanói e os diversos escores da BAMT-UFMG ficaram abaixo de 0.442 e não atingiram níveis de significância estatística (vide Tabela 12).

Com os participantes da Amostra 6 (vide Tabelas $1 \mathrm{e}$ 2) e para algumas tarefas (torre de Hanói, WCST, tarefa de associação de pares face-nome e o teste de discriminação de listas) foram realizadas duas aplicações independentes, uma antecedendo e outra sucedendo a um programa de treinamento cognitivo (vide Wood e cols., 2000). Isto possibilitou o cálculo adicional de correlações entre a segunda aplicação destas tarefas e uma segunda aplicação da BAMT-UFMG. Os resultado das correlações entre a segunda aplicação das tarefas-critério e da BAMT-UFMG evidenciou com maior nitidez o padrão de superposição parcial entre o desempenho em memória de trabalho e as funções executivas, bem como a dissociação entre os desempenhos em memória de trabalho e memória associativa. O padrão de correlações entre os resultados do pós-teste também pode ser interpretado como resultado de um efeito de prática com tarefas cognitivas obtido com programas de treinamento cognitivo. É possível que a prática com as tarefas cognitivas tenha sido útil aos participantes quanto à alocação de recursos cognitivos necessários para o desempenho de cada uma das tarefas realizadas (ver p. ex., Baltes \& Lindenberger, 1988; Oswald, Rupprecht, Gunzelmann \& Tritt, 1996). Com a prática das tarefas, a alocação de recursos torna-se mais eficiente e as relações entre os diversos processos cognitivos subjacentes à realização de cada tarefa ficam mais bem evidenciadas e como conseqüência o padrão de correlações entre os desempenhos nas tarefas fica mais claramente delineado.

A Amostra 5 (vide Tabelas 1 e 2), composta por participantes idosos, realizou o teste das matrizes progressivas de Raven segundo o procedimento padronizado de aplicação, com tempo livre para execução do teste. Um total de 38 participantes concluiu a testagem. Com a amostra 6, composta por estudantes secundaristas, foi possível, por outro lado, utilizar a escala avançada do tese das matrizes progressivas de Raven, o que permitiu calcular as correlações entre os escores nesta escala avançada os da BAMT-UFMG . As Tabelas 14 e 15 mostram os índices de correlação entre a BAMT-UFMG e o teste de Raven, respectivamente para amostra de idosos e de secundaristas e para as escalas geral e avançada.

Tabela 13. Correlações entre os Escores Compostos da BAMT-UFMG e as Tarefas-Critério para Avaliação da Validade Convergente e Divergente por Ocasião do Pós-Teste

\begin{tabular}{llllllll}
\hline & & Coord & Armaz & Effic & Num & Verb & Geral \\
\hline Funções Executivas & Torre de Hanói & 0,324 & 0,104 & 0,061 & 0,154 & 0,194 & 0,182 \\
& $(n=19)$ & n.s. & n.s. & n.s. & n.s. & n.s. & $\begin{array}{l}\text { n.s. } \\
\text { MCST }\end{array}$ \\
Memória Episódica & $0,662^{* *}$ & $0,603^{* *}$ & $0,480^{*}$ & $0,687 * * *$ & $0,554^{* *}$ & $0,666^{* *}$ \\
& $(n=19)$ & & & & & & \\
& Reconhecimento Pictorial & 0,059 & 0,203 & 0,303 & 0,182 & 0,245 & 0,224 \\
& $(\mathrm{n}=17)$ & n.s. & n.s. & n.s. & n.s. & n.s. & n.s. \\
& Reconhecimento Verbal & 0,229 & 0,297 & 0,337 & 0,320 & 0,307 & 0,333 \\
& $(n=17)$ & n.s. & n.s. & n.s. & n.s. & n.s. & n.s. \\
& Recenticidade Pictorial & 0,400 & 0,319 & 0,025 & 0,262 & 0,230 & 0,262 \\
& $(n=17)$ & n.s. & n.s. & n.s. & n.s. & n.s. & n.s. \\
& Recenticidade Verbal & $0,510^{*}$ & 0,408 & 0,259 & 0,460 & 0,357 & 0,437 \\
& $(n=17)$ & & n.s. & n.s. & n.s. & n.s. & n.s. \\
& Associação de Pares Face- & 0,183 & 0,177 & $-0,119$ & 0,109 & 0,032 & 0,080 \\
& Nome $(n=19)$ & n.s. & n.s. & n.s. & n.s. & n.s. & n.s. \\
\hline
\end{tabular}

Coord - Capacidade de Coordenação de Operações, Armaz - Capacidade de Armazenagem, Effic- Eficiência de Processamento de Informação, Num - Escore Numérico, Verb - Escore Verbal, Geral - Escore Geral, * Correlação Significativa ao nível de $p=0,05$; ** Correlação Significativa ao nível de $p=0,01 ; * * *$ Correlação Significativa ao nível de $p=0,001$, n.s.- correlação não significativa. 
Os padrões de correlação, mais significativos tanto para os escores brutos (Escala Geral: para ATM $r=0,415$, para SENT $r=0,454$; Escala Avançada; para ATM $r=0,314$, para SENT $r=0,332$; todos $p=0,001)$ quanto para o escore composto derivado de eficiência de processamento $(r=0,479, p=0,001$, para e a escala geral, e $r=0,365, p=0,001$ para a escala avançada), sugerem que a relação entre o nível de inteligência fluida e o desempenho na BAMT-UFMG ocorre através da eficiência de processamento. Há outras evidências na literatura quanto à associação entre a velocidade de processamento e a inteligência fluida (ver p. ex., Salthouse, 1996). O escore verbal também apresentou uma correlação moderada significativa com a inteligência, porém, o único escore bruto que compõe este fator e que se correlaciona à inteligência fluida é também uma tarefa de eficiência de processamento (compreensão de frases).

\section{Discussão}

Apesar de os resultados obtidos até agora serem encorajadores, é importante ressaltar que este projeto está em andamento. Em primeiro lugar, o trabalho conseguiu mostrar que os procedimentos são adequados para a testagem com a população brasileira, das mais variadas faixas etárias e níveis sócio-educacionais. Resultados obtidos por Wood (2000) mostram também que os escores variam em função da faixa etária, havendo melhora da performance quando os adolescentes são

Tabela 14. Correlações entre os Desempenhos dos Indivíduos Idosos nos Escores Compostos e Brutos da BAMTUFMG e o Desempenho no Teste das Matrizes Progressivas de Raven - Escala Geral

\begin{tabular}{lllllll}
\hline$n=38$ & Coord & Armaz & Effic & Num & Verb & Geral \\
\hline Raven - Escala Geral & 0,300 & 0,185 & $0,479^{* *}$ & 0,363 & $0,442^{* *}$ & $0,460^{* *}$ \\
& ALCCOM & $\begin{array}{l}\text { n.s. } \\
\text { APRD }\end{array}$ & ATM & ALCESC & APRP & SENT \\
Raven - Escala Geral & $\begin{array}{l}0,167 \\
\text { n.s. }\end{array}$ & $\begin{array}{l}0,053 \\
\text { n.s. }\end{array}$ & $0,415^{* *}$ & 0,264 & 0,265 & $0,454^{* *}$ \\
& & & n.s. & n.s. & \\
\hline
\end{tabular}

Coord - Capacidade de Coordenação de Operações, Armaz - Capacidade de Armazenagem, Effic- Eficiência de Processamento de Informação, Num - Escore Numérico, Verb - Escore Verbal, Geral - Escore Geral, Alccom - Alcance de Computação, Aprd - Listas de Números, Atm - Compreensão Aritmética, Alcesc - Alcance de Compreensão na Escuta, Aprp - Listas de Palavras, Sent - Compreensão de Frases, ${ }^{*}$ Correlação Significativa ao nível de $p=0,05 ; * *$ Correlação Significativa ao nível de $p=0,01$; ${ }^{* * *}$ Correlação Significativa ao nível de $p=0,001$, n.s.- correlação não significativa.

Tabela 15. Correlações entre os Desempenhos dos Estudantes Secundaristas nos Escores Compostos e Escores Brutos da BAMT-UFMG e o Desempenho no Teste das Matrizes Progressivas de Raven - Escala Avançada

\begin{tabular}{lllllll}
\hline N=63 & Coord & Armaz & Effic & Num & Verb & Geral \\
Raven - Escala Avançada & $\begin{array}{l}0,239 \\
\text { n.s. }\end{array}$ & $\begin{array}{l}0,063 \\
\text { n.s. }\end{array}$ & $0,365^{* *}$ & 0,167 & $0,368^{* *}$ & $0,311^{*}$ \\
& ALCCOM & APRD & ATM & ALCESC & APRP & SENT \\
Raven - Escala Avançada & $\begin{array}{l}0,123 \\
\text { n.s. }\end{array}$ & $\begin{array}{l}\text { - } 0,009 \\
\text { n.s. }\end{array}$ & $0,314 * *$ & $0,251^{*}$ & 0,160 & $0,332^{* *}$ \\
& & & & n.s. & \\
\hline
\end{tabular}

Coord - Capacidade de Coordenação de Operações, Armaz- Capacidade de Armazenagem, Effic - Eficiência de Processamento de Informação, Num - Escore Numérico, Verb - Escore Verbal, Geral - Escore Geral, Alccom - Alcance de Computação, Aprd - Listas de Números, Atm - Compreensão Aritmética, Alcesc - Alcance de Compreensão na Escuta, Aprp- Listas de Palavras, Sent - Compreensão de Frases, ${ }^{*}$ Correlação Significativa ao nível de $p=0,05$; ** Correlação Significativa ao nível de $p=0,01$; $* * *$ Correlação Significativa ao nível de $p=0,001$, n.s.- correlação não significativa. 
comparados com os adultos e decréscimo quando os adultos jovens são comparados com os participantes idosos.

Quanto aos parâmetros psicométricos, comecemos por analisar os escores de fidedignidade, os quais parecem ser bastante razoáveis. Temos razões para crer, entretanto, que os escores de fidedignidade possam ter sido supervalorizados como soe acontecer com os escores de consistência interna para tarefas cronometradas (ver p. ex., Retzlaff \& Gibertini, 1994). Diversos autores têm sugerido que a velocidade de processamento é o fator mais importante no esclarecimento das diferenças de variância relacionadas à idade em diversos tipos de tarefas cognitivas, mas principalmente na memória de trabalho (ver p.ex., Salthouse \& Babcock, 1991; Salthouse, 1996; Fry \& Hale, 1996). Desta forma, a fidedignidade para os aspectos relacionados com o armazenamento deve ser bem mais baixa do que o estimado (ver p. ex. Retzlaff \& Gibertini, 1994). Nós podemos pensar em duas alternativas para continuar investigando esta questão. Por um lado, será necessário utilizar a metodologia de testereteste para obter escores mais realísticos de fidedignidade. De outra parte, seria possível dissociar os componentes velocidade de processamento e timing, variando o tempo de retardo, como é feito no procedimento de BrownPeterson (Brown, 1958; Peterson \& Peterson, 1959). O tempo de retardo está fixado atualmente em 4 segundos por item alvo, mas pode ser aumentado ou diminuído. Desta forma, poderíamos investigar sistematicamente a contribuição dos componentes de armazenamento e de eficiência ou velocidade de processamento para a fidedignidade do teste.

A análise fatorial sugeriu uma estrutura unifatorial para a BAMT-UFMG. Este resultado está de acordo com os resultados obtidos por Salthouse e Babcock (1991), os quais, utilizando análises de regressão múltipla e modelos de equações estruturais, identificaram o referido fator como sendo relacionado à velocidade de processamento. Dados revisados por Salthouse (1996) indicam que a velocidade de processamento explica cerca de $90 \%$ da variância relacionada ao envelhecimento cognitivo em um série de tarefas distintas. Apesar de admitirem a importância da velocidade de processamento, outros autores têm sugerido uma estrutura bifatorial para explicar a variância relacionada ao envelhecimento cognitivo. Mayr, Kliegl e Krampe (1996) utilizaram um paradigma experimental que lhes permitiu dissociar os componentes de performance relacionados à velocidade de processamento daqueles relacionados à coordenação de operações. Os dados destes pesquisadores sugerem que a velocidade de processamento aumenta muito entre a adolescência e a idade adulta, mas diminui proporcionalmente muito menos entre a idade adulta e a velhice. Já a performance relacionada à coordenação de operações apresentou um decréscimo acentuado entre a idade adulta jovem e a velhice. Halford, Maybery, O'Hare e Grant (1994), trabalhando com procedimento psicométricos, também têm chamado atenção para a importância da complexidade relacional no desenvolvimento da memória de trabalho. Dados revisados por Deary e Caryl (1997) indicam, por outro lado, que a relação entre velocidade de processamento e a estrutura morfofuncional do sistema nervoso central não é mediada simples e diretamente por fenômenos biofísicos tais como a constante de membrana ou a velocidade de condução nervosa. A relação entre inteligência, velocidade de processamento e as características biofísicas do cérebro parece ser bastante complexa e mediada por efeitos de rede, ou seja, pela dinâmica de interação dependente de atividade.

Resta discutir os aspectos relacionados à validade concordante e discordante. As correlações observadas entre os diversos processos-construto e a performance nas testagens de inteligência fluida é representada esquematicamente na Figura 3. Dos três processos componentes da BAMT-UFMG - eficiência de processamento, capacidade de armazenagem e coordenação de operações - apenas a eficiência de processamento apresentou correlações significativas com a performance no teste de Raven. Estes resultados sugerem que a relação entre inteligência e memória de trabalho seja mediada pela velocidade de processamento, tal como proposto por Salthouse (ver p. ex., Salthouse \& Babcock,1991; Salthouse, 1996).

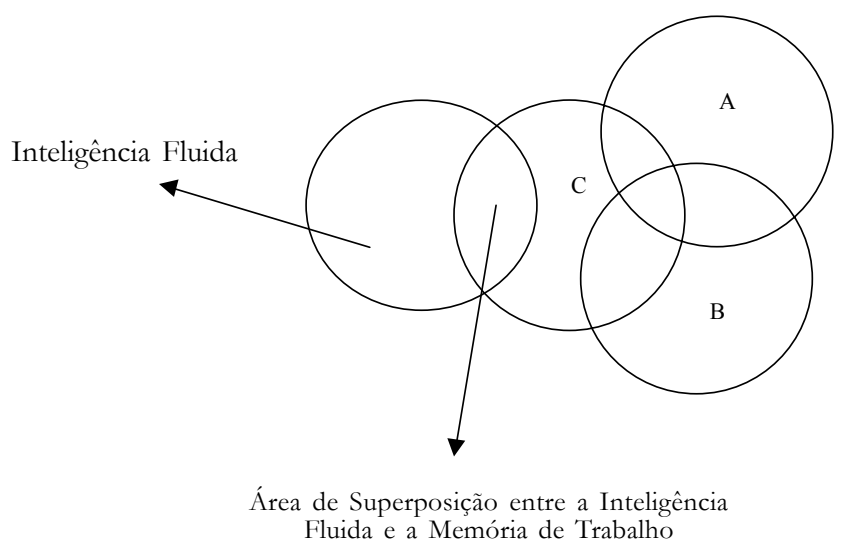

Figura 3. Representação esquemática das relações empíricas entre os construtos memória de trabalho e inteligência fluída (A: capacidade de coordenação de operações, B: capacidade de armazenamento de informações e C: capacidade de processamento de informação) 
As correlações entre o desempenho na BAMTUFMG e as tarefas-critério para validade convergente e divergente indicam, conforme esperado, que a performance na bateria se correlaciona significativamente com a performance em pelo menos um teste de função executiva (o WCST) e com nenhuma das medidas de memória episódica (vide Figura 4). Nós não temos nenhuma explicação convincente para o fato de as performances na BAMT e na torre de Hanói não terem se correlacionado. Uma possibilidade é a ocorrência de efeito de teto, o qual foi observado no pós-teste. Como a tarefa com três argolas se revelou adequada no préteste, e não tínhamos a expectativa de que a performance fosse muito acima disto, não utilizamos um problema com quatro ou cinco argolas no pós-teste. Uma outra possibilidade poderia ser que a torre de Hanói envolve menos componentes de memória de trabalho do que a torre de Londres, a sua tarefa homóloga e mais flexível no que se refere à decomposição da carga de memória de trabalho (Krikorian, Bartok \& Gay, 1991).

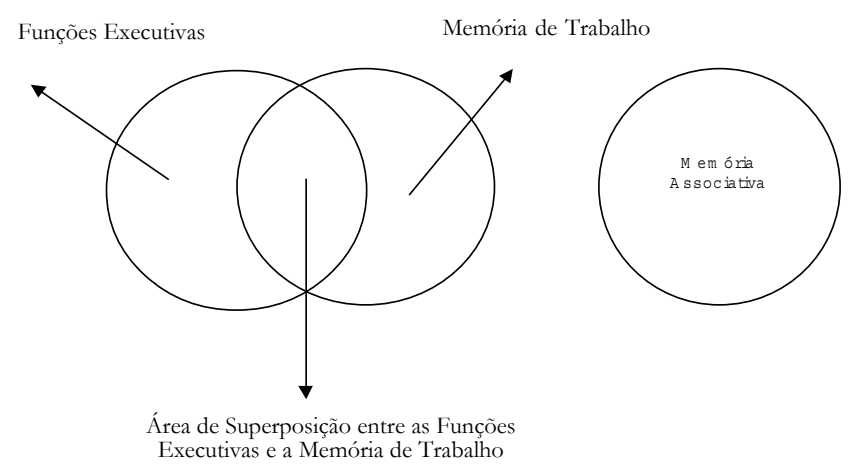

Figura 4. Representação esquemática das relações empíricas entre a memória de trabalho e os construtos funções executivas e memória associativa episódica

A falta de correlação com as tarefas de memória de reconhecimento do Teste de Discriminação de Listas (TDL-UFMG) era esperada e indica que a BAMTUFMG não está medindo o construto memória episódica. A falta de correlação com as medidas de memória para ordem temporal no TDL-UFMG é mais problemática. Alguns autores, como por exemplo, Mangels (1997), acreditam que a memória para ordem temporal reflita a atuação de algum componente de alto nível do funcionamento executivo, relacionado à capacidade de solução de problemas ou capacidade de pensamento estratégico. Neste caso deveria haver correlação com os escores da BAMT-UFMG. Uma outra alternativa seria considerar a capacidade seqüenciação ou ordenação temporal como um processo específico, implementado por circuitos relacionados às regiões dorsolateral do córtex frontal (Milner, McAndrews \& Leonard, 1990; Petrides, 1991). Uma proposição mais antiga é, inclusive, de que a memória para ordem temporal envolveria processamento automático (Hasher \& Zacks, 1979), sendo apoiada mais recentemente por dados de simulação com redes neurais (Brown, Preece \& Hulme, 2000). Neste caso não haveria necessidade de correlação com os escores da BAMT-UFMG. Os dados obtidos com a BAMTUFMG estão de acordo com a hipótese de que a memória para ordem temporal envolve redes ou padrões de ativação neuronal diversos daqueles recrutados pelo funcionamento executivo em outros domínios.

Finalmente, gostaríamos de encerrar comentando que a próxima etapa do nosso trabalho é examinar a utilidade clínica da BAMT-UFMG. Estamos, atualmente, investigando suas características em uma amostra de indivíduos portadores de esclerose múltipla. As possibilidades de aplicação clínica são bastante amplas, uma vez que indivíduos portadores de diversas patologias cerebrais adquiridas e do desenvolvimento apresentam problemas relacionados à velocidade de processamento e memória de trabalho, como por exemplo Parkinson, Alzheimer, traumatismo crânio-encefálico, dislexias específicas de evolução, afasias etc. O reconhecimento destes déficits cognitivos, muitas vezes sutis, pode desempenhar um papel importante na reabilitação inclusive psicossocial destas pessoas (ver p.ex., Godfrey, Knight, Marsh, Moroney \& Bishara, 1989).

\section{Referências}

Baddeley, A. D. (1992a). Is working memory working? Quarterly Journal of Experimental Psychology, 44A, 1-31.

Baddeley, A. D. (1992b). Working memory. Science, 255, 556-559.

Baddeley, A. D. \& Thomson, N. \& Buchanan, M. (1975). Word length and the structure of short-term memory. Journal of Verbal Learning and Verbal Behavior, 14, 575-589.

Baltes, P. B. \& Lindenberger, U. (1988). On the range of cognitve plasticity in old age as a function of experience: 15 years of intervention research. Behavior Therapy, 19, 283-300.

Birren, J. E. \& Fisher, L. M. (1995). Aging and speed of behavior: Possible consequences for psychological functioning. Annual Review of Psychology, 46, 329-353.

Brown, J. (1958). Some tests of the decay theory of immediate memory. Quarterly Journal of Experimental Psychology, 10, 12-21.

Brown, G.D.A., Preece, T. \& Hulme, C. (2000). Oscillator-based memory for serial order. Psychological Review, 107, 127-181.

Caplan, D., Hildebrandt, N. \& Makris, N. (1996). Location of lesions in stroke patients with deficits in syntactic processing in sentence comprehension. Brain, 119, 933-949.

Caplan, D., Rochon, E. \& Waters, G. S. (1992). Articulatory and phonological determinants of word length effects in span tasks. Quarterly Journal of Experimental Psychology [A], 45, 177-192. 
Carpenter, P. A., Just, M. A. \& Shell, P. (1990). What one intelligence test measures: a theoretical account on the processing in the Raven progressive matrices test. Psychological Review, 97, 404-431.

Carpenter, P. A.; Just, M. A. \& Reichle, E. D. (2000). Working memory and executive function: evidence from neuroimaging. Current Opinion in Neurobiology, 10, 195-1990.

Carpenter, P., Miyake, A. \& Just, M. A. (1994). Working memory constraints in comprehension: evidence from individual differences, aphasia, and aging. Em M. A. Gernsbacher (Org.), Handbook of psycholinguistics (pp. 1075-1122). San Diego: Academic.

Cowan, N. (1988). Evolving conceptions of memory storage, selective attention, and their mutual constraints within the human information processing system. Psychological Bulletin, 104, 163-191.

Daneman, M. \& Carpenter, P. A. (1980). Individual differences in working memory and reading. Journal of Verbal Learning and Verbal Behavior, 19, 450-466.

Deary, I. J. \& Caryl P. G. (1997). Neuroscience and human intelligence differences. Trends in Neurosciences, 20, 365-370.

Del Nero, H. S. (1997). O sítio da mente: Pensamento, emoção e vontade no cérebro bumano. São Paulo: Collegium Cognitio.

Ericsson, K. A. \& Kintsch, W. (1995). Long-term working memory. Psychological Review, 102, 211-245.

Forster, K. I. \& Chambers, S. M. (1973). Lexical access and naming time. Journal of Verbal Learning and Verbal Behavior, 12, 627-635.

Fry, A. F. \& Hale, S. (1996). Processing speed, working memory, and fluid intelligence: evidence for a developmental cascade. Psychological Science, 7, 237-241

Fuster, J. M. (1995). Memory in the cerebral cortex. An empirical approach to neural networks in the buman and nonhuman primate. Cambridge, MA: MIT Press.

Garnsey, S. M., Pearlmutter, N. J., Myers, E. \& Lotocky, M. A. (1997). The contributions of verb bias and plausibility to the comprehension of temporarily ambiguous sentences. Journal of Memory and Language, 37, 58-93.

Gathercole, S. E. (1998) The development of memory. Journal of Child Psychology and Psychiatry, 39, 3-27.

Godfrey, H. P. D., Knight, R. G., Marsh, N. V., Moroney, B. \& Bishara, S. N. (1989). Social interaction and speed of information processing following very severe head injury. Psychological Medicine, 19, 175-182.

Goldman-Rakic, P. S. (1996). Regional and cellular fractionation of working memory. Proceedings of the National Academy of Sciences (USA), 93, 1347313480.

Gough, P. B. (1965). Grammatical transformations and speed of understanding. Journal of Verbal Learning and Verbal Behavior, 4, 107-111.

Haase, V. G. (2000). Modelos de correlação anátomo-clínica em neuropsicologia do desenvolvimento. Em V. G. Haase, R. Rothe-Neves, C. Käppler, M. L. M. Teodoro \& G. M. O. Wood (Orgs.), Psicologia do desenvolvimento: Contribuições interdisciplinares (pp. 17-65). Belo Horizonte: Health.

Haase, V. G., Diniz, L. F. M. \& da Cruz, M. F. (1997). A estrutura temporal da consciência. Psicologia USP, 8, 227-250.

Haken, H. \& Haken-Krell, M. (1997). Gehirn und Verhalten. Unser Kopf arbeitet anders, als wir denken. Stuttgart: Deutsche Verlags-Anstalt.

Halford, G. S., Maybery, M. T., O’Hare, A.W. \& Grant, P. (1994). The development of memory and processing capacity. Child Development, 65, 13381356.

Hasher, L. \& Zacks, R.T. (1979). Automatic and effortful processes in memory. Journal of Experimental Psychology: General, 106, 356-388.

Heaton, S. K. \& Thompson, L. L. (1993). Wisconsin Card Sorting Test: Individual practice in administration and scoring. Odessa, FL: Psychological Assessment Resources.

Heaton, R. K., Chelune, G. J., Talley, J. L., Kay, G. C. \& Curtiss, G. (1993). Wisconsin Card Sorting Test Manual. Revised and expanded. Odessa, FL: Psychological Assessment Resources.

Klahr, D. \& Robinson, M. (1980) Formal assessment of problem-solving and planning processes in preschool children. Cognitive Psychology, 13, 113-148.
Krikorian, R., Bartok, J. \& Gay, N. (1991). Tower of London procedure: a standard method and developmental data. Journal of Clinical and Experimental Neuropsychology, 16, 840-850.

Kounios, J. \& Holcomb, P. J. (1994). Concreteness effects in semantic processing: ERP evidence supporting dual-coding theory. Journal of Experimental Psychology: Learning, Memory, and Cognition, 20, 804-823.

Kyllonen, P. C. \& Chrystal, R. E. (1990). Reasoning ability is (little more than) working memory capacity?! Intelligence, 14, 389-433.

Lacerda, S. S. \& Haase, V. G. (2000). Exame neuropsicológico da memória de reconhecimento e da memória de recenticidade. Em V. G. Haase, R. Rothe-Neves, C. Käppler, M. L. M. Teodoro \& G. M. O. Wood (Orgs.), Psicologia do desenvolvimento: Contribuições interdisciplinares (pp. 161178). Belo Horizonte: Health.

MacDonald, M. C., Pearlmutter, N. J. \& Seidenberg, M. S. (1994). The lexical nature of syntactic ambiguity resolution. Psychological Review, 101, 676-703.

Mangels, J.A. (1997). Strategic processing and memory for temporal order in patients with frontal lobe lesions. Neuropsychology, 11, 207-221.

Mayr, U., Kliegl, R. \& Krampe, R. T. (1996). Sequential and coordinative processing dynamics in figural transformations across the life span. Cognition, 59, 61-90.

McCarthy, D. (1980). Investigation of a visual imagery mnemonic device for acquiring face-name associations. Journal of Experimental Psychology: Human Learning and Memory, 6, 145-155.

Milner, B., McAndrews, M.P. \& Leonard, G. (1990). Frontal lobes and memory for the temporal order of recent events. Cold Spring Harbor Symposia on Quantitative Biology, 55, 987-994.

Müller, H. M., King, J. W. \& Kutas, M. (1997). Event-related potentials elicited by spoken relative clauses. Cognitive Brain Research, 5, 193-203.

Oswald, W. D., Rupprecht, R., Gunzelmann, T. \& Tritt, K. (1996). The SIMA-project: effects of 1 year cognitive and psychomotor training on cognitive abilities of the elderly. Behavioral Brain Research, 78, 67-72.

Owen, A.M. (1997). The functional organization of working memory processes within human lateral frontal cortex: The contribution of functional neuroimaging. European Journal of Neuroscience, 9, 1329-1339.

Owen, A. M., Stern, C. E., Look, R. B., Tracey, I., Rosen, B. R. \& Petrides, M. (1998). Functional organization of spatial and nonspatial working memory processing within the human lateral frontal cortex, Proceedings of the National Academy of Sciences (USA), 955, 7721-7726.

Pasquali, L. (1997). Psicometria: Teoria e aplicações. Brasília: Editora da UnB.

Pearlmutter, N. J., Daugherty, K., MacDonald, M. C. \& Seidenberg, M. S. (1994). Modeling the use of frequency and contextual biases in sentence processing. Proceedings of the 16th Annual Conference of the Cognitive Science Society, 699-704.

Petrides, M. (1991). Functional specialization within the dorsolateral frontal cortex for serial order memory. Proceedings of the Royal Society of London B, 246, 299-306.

Petrides, M. (1995). Functional organization of the human frontal cortex for mnemonic processing. Annals of the New York. Academy of Sciences, 769, 85-96.

Peterson, L. R. \& Peterson, M. J. (1959). Short-term retention of individual items. Journal of Experimental Psychology, 61, 12-21.

Pinheiro, A. M. V. (1996). Contagem de freqüencia de palavras em cartilhas do préescolar à $4^{a}$ série. Belo Horizonte: MPS Informática. (software).

Pöppel, E. (1994). Temporal mechanisms in perception. International Review of Neurobiology, 37, 185-202.

Raven, J.C. (1965). Advanced Progressive Matrices. Sets I and II. London: H.K. Lewis.

Raven, J.C. (1997). Testes das Matrizes Progressivas. Escala Geral. Rio de Janeiro: CEPA.

Rayner, K. (1977). Visual attention in reading: Eye movements reflect cognitive processes. Memory \& Cognition, 4, 443-448.

Rayner, K. \& Sereno, S. C. (1994). Eye movements in reading: Psycholinguistic studies. Em M. A. Gernsbacher (Org.), Handbook of psycholinguistics (pp. 57-81). San Diego: Academic. 
Recht, D. L. \& Leslie, L. (1988). Effect of prior knowledge on good and poor readers' memory of text. Journal of Educational Psychology, 80, 1620.

Retzlaff, P. D. \& Gibertini, M. (1994). Neuropsychometric issues and problems. Em R.D. Vanderploeg (Org.), Clinician's guide to neuropsychological assessment (pp. 185-210). Hillsdale: Erlbaum.

Reuter-Lorenz, P. A., Jonides, J., Smith, E. E., Hartley, A., Miller, A., Marshuetz, C. \& Koeppe, R. A. (2000). Age differences in the frontal lateralization of verbal and spatial working memory revealed by PET. Journal of Cognitive Neuroscience, 12, 174-187.

Rijsdijk, F. V., Vernon, P. A. \& Boomsma, D. I. (1998). The genetic basis of the relation between speed-of-information-processing and IQ. Behavioural Brain Research, 95, 77-84.

Rochon, E., Waters, G. S. \& Caplan, D. (1994). Sentence comprehension in patients with Alzheimer's disease. Brain and Language, 46, 329-349.

Rothe-Neves, R. (2000). Processamento sintático e memória de trabalho. Em V.G. Haase, R. Rothe-Neves, C. Käppler, M. L. M. Teodoro \& G. M. O. Wood (Orgs.), Psicologia do desenvolvimento: Contribuiç̃os interdisciplinares (pp. 111-119). Belo Horizonte: Health.

Salthouse, T. A. (1996). The processing-speed theory of adult age differences in cognition. Psychological Bulletin, 103, 403-428.

Salthouse, T. A. \& Babcock, R. L. (1991). Decomposing adult age differences in working memory. Developmental Psychology, 27, 763-776.

Sarnthein, J., Petsche, H., Rappelsberger, P., Shaw, G. L. \& von Stein, A. (1998). Synchronization between prefrontal and posterior association cortex during human working memory. Proceedings of the National Academy of Sciences (USA), 95, 7092-7096.

Schneider, W., Korkel, J. \& Weinert, F. E. (1989). Domain-specific knowledge and memory performance. A comparison of high- and low-aptitude children. Journal of Educational Psychology, 81, 306-312.

Singer, W. (1998) Consciousness and the structure of neuronal representations. Philosophical Transactions of the Royal Society of London B, 353, 1829-1840.

Slobin, D. I. (1965). Grammatical transformations and sentence comprehension in childhood and adulthood. Journal of Verbal Learning and Verbal Behavior, 5, 219-227.

Smith, E. E. \& Jonides, J. (1998). Neuroimaging analyses of human working memory. Proceedings of the National Academy of Sciences (USA), 95, 1206112068.

Teixeira, J. F. (1998). Mentes e máquinas: Uma introducão à ciência cognitiva. Porto Alegre: Artes Médicas.
Torgesen, J. K. (1996). A model of memory from an information processing perspective: the special case of phonological memory. Em G. R. Lyon \& N. A. Krasnegor (Orgs.), Attention, memory, and executive function (pp. 157-184). Baltimore: Paul H. Brookes.

Trueswell, J. C., Tanenhaus, M. K. \& Kello, C. (1993). Verb-specific constraints in sentence processing: separating effects of lexical preference from garden-paths. Journal of Experimental Psychology: Language, Memory and Cognition, 19, 528-553.

Verhaeghen P. \& Salthouse T. A. (1997). Meta-analyses of age-cognition relations in adulthood: estimates of linear and nonlinear age effects and structural models. Psychological Bulletin, 122, 231-49.

Wagner, R. K. (1996) From simple structure to complex function. Major trends in the development of theories, models, and measurements of memory. Em G. R. Lyon \& N. A. Krasnegor (Orgs.), Attention, memory, and executive function (pp. 139-156). Baltimore: Paul H. Brookes.

Waters, G. S. \& Caplan, D. (1996). The measurement of verbal memory capacity and its relation to reading comprehension. Quarterly Journal of Experimental Psychology [A], 49, 51-75.

West, R. L. (1996). An application of prefrontal cortex function theory to cognitive aging. Psychological Bulletin, 120, 272-292.

Wood, G. M. O. (2000). Efeitos de programas de treinamento e dos niveis de autoeficácia percebida sobre a capacidade de memória de trabalho de indivíduos idosos. Dissertação de Mestrado não-publicada. Curso de Pós-Graduação em Psicologia Social, Universidade Federal de Minas Gerais. Belo Horizonte, MG.

Wood, G. M. O., Rothe-Neves, R., Scalioni, I. G., Araújo, J. R., Lima, E. P. \& Haase, V. G. (1999). Elementos para a validação de uma bateria para a investigação da memória de trabalho: testagem individual x testagem coletiva (Abstract). Em Sociedade Brasileira de Psicologia (Org.), Resumos de comunicações científicas, XXIX Reunião Anual de Psicologia (p. 234). Campinas: SBP.

Wood, G. M. O., Haase, V. G., Araújo, J. R., Scalioni, I. G., Lima, E. P. \& Sampaio, J. R. Desenvolvimento cognitivo adulto: a Avaliação e a reabilitação da capacidade de memória de trabalho. Em V. G. Haase, R. Rothe-Neves, C. Käppler, M. L. M. Teodoro \& G. M. O. Wood (Orgs.), Psicologia do desenvolvimento: Contribuições interdisciplinares (pp. 121-144). Belo Horizonte: Health.

Sobre os autores:

Guilherme Maia de Oliveira Wood é Psicólogo e Mestre em Psicologia Social pela UFMG, Doutorando em Neuropsicologia pela Universidade de Aachen.

Maria Raquel Santos Carvalho é Médica Geneticista, Professora Assistente no Departamento de Biologia Geral da UFMG, Mestre em Genética pela UFRGS, Doutoranda em Genética pela Universidade de Munique.

Rui Rothe-Neves é Professor do Departamento de Psicologia da Universidade Federal de Minas Gerais - UFMG, Mestre e Doutorando em Estudos Lingüísticos pela UFMG.

Vitor Geraldi Haase é Médico Neurologista, Professor Adjunto no Departamento de Psicologia da UFMG, Coordenador do Laboratório de Neuropsicologia do Desenvolvimento da UFMG, Mestre em Lingüistica pela PUCRS e Doutor em Biologia Humana pela Universidade de Munique. 